\title{
Spatial Disparity of Health Environment Level and Its Influencing Factors in China
}

\author{
Ke Wen, Xueqian Song ${ }^{*}$, Huayue Long \\ School of Management, Chengdu University of Information Technology, Chengdu, Sichuan, China
}

Keywords: Health environment; Entropy-weighted AHP method; Spatial autocorrelation model; Influencing factors

\begin{abstract}
Health is essential to national welfare and people's livelihood, and healthy environment is conducive to promote a healthy population. This paper constructed a health environment index system and applied the entropy-weighted analytic hierarchy process method, spatial autocorrelation Moran's index (Moran's I) and econometric model based on the environmental and socio-economic data in 31 provinces in 2017 to evaluate the spatial pattern of the levels of health environment and its influences in China. The results show that, 1). There are significant spatial differences in the level of health environment in China, the overall level is mainly higher and unevenly distributed, with a significant spatial aggregation effect. North China and surrounding provinces are low-value aggregation areas, and high-value aggregation areas are mainly distributed in Guangdong. Guangxi, Hainan, 2). The multiple regression model optimized by stepwise regression method shows that in 2017, urban per capita disposable income plays a significantly positive role in the levels of health environment value, while the ratio of the secondary and tertiary industries to GDP, and population density have significant negative impacts. Conclusion, in 2017, there are obvious spatial inequity existing of the levels of health environment in China, and it is affected by many factors. In order to further improve the overall level of health environment, targeted policies should be made according to the influencing factors.
\end{abstract}

\section{Introduction}

Health is the foundation of human survival and development, it is related to national security and social stability [1]. Today, major public health events have become one of the main factors affecting health. With the emergence of negative urbanization problems in China, such as, disease spread [2], environmental pollution caused by industrialization [3], and the health problems of aging population [4], people's health will be severely challenged. From the perspective of human rights, the World Health Organization (WHO, 2018) regards the living environment as one of the determinants of people's health. In order to promote the health of the people, the Outline of Healthy China 2030 Plan regards improving the quality of the environment as an important part of creating a healthy environment. It can be seen that a healthy environment has a positive effect on public health. With health geography took social environment as the research focus to affect the health of population [5], it means that the regional environment is increasingly affected by economic, social and other aspects. Due to the gap in China's socioeconomic level, the environmental characteristics have different regional Disparity. Therefore, an objective and scientific establishment of a healthy environment assessment system, exploring the environmental levels and spatial distribution characteristics of China's regions, and analysing their influencing factors are of great significance for understanding the status of China's healthy environmental levels and promoting population health. The current research on environment and health can be sorted out from three levels, disciplinary progress, research content, and research methods. On the progress of the discipline, traditional medical geography mainly studies the geographical distribution of diseases and health conditions of populations, the occurrence, prevalence of diseases, and the relationship between health conditions and geographical environment. The purpose is to create a beautiful environment most suitable for human life [6]. With the transformation of social culture, traditional medical 
geography has turned to health geography, emphasized the construction of a healthy social environment [5,7] and studied the dynamic change mechanism of the impact of urban geographic systems on health [8]. In terms of research content, Based on the discipline, most scholars study the natural environment [9], the physical [10-12] and psychological [13-14] effects of the built environment on different age [15-16] gender groups [17-18], and environmental issues such as air pollution and water pollution [19], there are some scholars who have constructed a living environment index system [20] and created a healthy environment space [21-22], however, the issue of environmental justice [23-25] is dominated by foreign scholars. In research methods, Zhang Yanji et al. [26] used the tendency value matching method to explore the impact of urban built environment on residents' health. Zhou Kan and Fan Jie [19] used cluster analysis, spatial autocorrelation analysis and econometric models to analyse the regional differences and influencing factors of environmental pollution sources. Existed research shows that most scholars attach great importance to China's environment-related issues, especially the impact on the health of the population. However, there is still a lack of overall recognition of China's health-oriented environmental quality. Based on this, this article uses the healthy city indicators officially released at different scales at the international, national, provincial and other levels as a reference to build a healthy environment indicator system for spatial analysis and discussion of influencing factors, hoping to create good environmental conditions for the promotion of population health, improve the country governance capabilities and governance system, to help build a healthy China.

\section{Data Sources and Research Methods}

\subsection{Data sources}

This paper takes 31 province-level administrative space units in China as research objects, an index system reflects the level of a healthy environment has been established, which reflects the proportion of days with excellent air quality, the average ambient air particulate matter (PM2.5) data, the surface water quality that reflects the water quality meets or exceeds the proportion of Class III water, and urban sewage centralized treatment rate comes from the 'Eco-Environment Bulletin' of the provinces (municipalities) in 2017 and the 'China City Statistical Yearbook' in 2018. The green coverage rate of built-up areas reflects the level of green space, the green space per capita of parks, the decontamination rate of urban domestic waste that reflects waste disposal, and the comprehensive utilization rate of general industrial solid waste, the per capita road area that reflects the level of basic public facilities, the number of buses per 10,000 people, and the penetration rate of clean energy (gas) come from the 'China Statistical Yearbook', 'China City Statistical Yearbook’, and 'China Environmental Statistics Yearbook’ in 2018.

\subsection{Research methods}

\subsubsection{Entropy-weighted AHP method}

AHP is a subjective weighting method for determining weights based on experience. The Entropy-weighted can objectively weight the existed index information of the data. The weights obtained by using one of the methods alone have certain deficiencies. Therefore, the obtained weights are combined to reflect the accurate weight values. On this basis, the non-dimensional index and the composite weight are combined to calculate the health environment level. AHP method is to build a hierarchical structure model of the indicator system, the upper-layer indicators are used as the criteria, and the judgment matrix is used to compare the indicators at the same level, the article scored by experts and believed that the indicators of the naturalness of the healthy environment should have a greater weight [27]. On the basis of the consistency test, Yaahp10.1 is used to calculate the weights of the indicators of the healthy environment. The entropy-weight method can give weight according to the size of the system index information entropy, and calculate the comprehensive level score based on the objective weight. In order to eliminate the dimension between different indicators, the data needs to be standardized, when the indicator is larger, the 
positive formula is used, when the indicator is smaller, the negative formula is used, and the calculation method is as follows [28].

Forward formula $\quad \mathrm{X}_{\mathrm{ij}}^{\prime}=\left(\mathrm{X}_{\mathrm{ij}}-\min \left\{\mathrm{X}_{\mathrm{j}}\right\}\right) /\left(\max \left\{\mathrm{X}_{\mathrm{j}}\right\}-\min \left\{\mathrm{X}_{\mathrm{j}}\right\}\right)$

Negative formula $\quad \mathrm{X}_{\mathrm{ij}}^{\prime}=\left(\max \left\{\mathrm{X}_{\mathrm{j}}\right\}-\mathrm{X}_{\mathrm{ij}}\right) /\left(\max \left\{\mathrm{X}_{\mathrm{j}}\right\}-\min \left\{\mathrm{X}_{\mathrm{j}}\right\}\right)$

Calculate the proportion of the $j$-th index value in the $\mathrm{i}$-th region $\mathrm{Y}_{\mathrm{ij}}=\mathrm{X}_{\mathrm{ij}}^{\prime} / \sum_{\mathrm{i}=1}^{\mathrm{m}} \mathrm{X}_{\mathrm{ij}}^{\prime}$

Calculation of index information entropye $e_{j}=-k \sum_{i=1}^{m}\left(Y_{i j} \times \ln Y_{i j}\right), k=1 / \operatorname{lnm}, \quad 0 \leq e_{j} \leq 1$

Redundancy calculation $\mathrm{d}_{\mathrm{j}}=1-\mathrm{e}_{\mathrm{j}}$

Weights $\quad \mathrm{w}_{\mathrm{i}}=\mathrm{d}_{\mathrm{i}} / \sum_{\mathrm{j}=1}^{\mathrm{n}} \mathrm{d}_{\mathrm{j}}$

Overall ratings $\mathrm{S}_{\mathrm{i}}=\sum_{\mathrm{j}}^{\mathrm{n}} \mathrm{w}_{\mathrm{i}} \times \mathrm{X}_{\mathrm{ij}}^{\prime}$

In the formula, $X_{i j}$ represents the $i$-th region, the value of the $j$-th evaluation index, $\min \left(X_{i}\right)$ and max $\left(\mathrm{X}_{\mathrm{i}}\right)$ are the minimum and maximum values of the $\mathrm{j}$-th evaluation index in all regions, where $\mathrm{m}$ is the number of evaluation regions, $n$ is the number of indicators.

After calculated the subjective and objective weights of each indicator in the health environment indicator layer through AHP method and Entropy-weighted, the combined weight formula is used to obtain the composite weight [29], the formula is as follows.

$$
\beta=\frac{\theta_{\mathrm{i}} \times \omega_{\mathrm{i}}}{\sum_{\mathrm{i}=1}^{\mathrm{m}} \theta_{\mathrm{i}} \times \omega_{\mathrm{i}}}
$$

In the formula, $\beta$ is the compound weight, $\theta_{\mathrm{i}}$ represents the Entropy-weighted weight, and $\omega_{\mathrm{i}}$ represents the AHP method weight.

\subsubsection{Exploratory spatial analysis (ESDA)}

The global spatial autocorrelation Moran index (Global Moran's I) is used to measure the spatial pattern of China's healthy environmental level and reveal whether there is agglomeration or dispersion in space, the calculation formula is as follows.

$$
\mathrm{I}=\frac{\left(\mathrm{n} \sum_{\mathrm{i}=1}^{\mathrm{n}} \sum_{\mathrm{j}=1}^{\mathrm{n}} \mathrm{C}_{\mathrm{ij}}\left(\mathrm{X}_{\mathrm{i}}-\overline{\mathrm{X}}\right)\left(\mathrm{X}_{\mathrm{j}}-\overline{\mathrm{X}}\right)\right)}{\left(\sum_{\mathrm{i}=1}^{\mathrm{n}} \sum_{\mathrm{j}=1}^{\mathrm{n}} \mathrm{C}_{\mathrm{ij}} \sum_{\mathrm{i}=1}^{\mathrm{n}}\left(\mathrm{X}_{\mathrm{i}}-\overline{\mathrm{X}}\right)^{2}\right)}
$$

Where $n$ is the number of observation points, $C$ is the spatial weight matrix, and $X_{i}$ is the attribute value of area $\mathrm{i}$. In this study, K-nearest neighbor method based on GeoDa 1.14.0 is used. The value range of Moran's I index is $[-1,1]$. When the value is positive, it indicates that the healthy environment level has spatial agglomeration correlation, the closer to 1 the higher the degree of agglomeration, when the value is negative, it indicates that the healthy environment level Spatial dispersion characteristics, the closer to -1 the higher the degree of dispersion, when the value is 0 , it indicates that the health environment level is not spatially related.

And test Moran's I, use standardized statistics to test the significance level of spatial autocorrelation [30].

$$
\mathrm{Z}(\mathrm{I})=(\mathrm{I}-\mathrm{E}(\mathrm{I})) / \sqrt{\operatorname{Var}(\mathrm{I})}
$$

In the formula, Var (I) is the theoretical variance of Moran's I index, E (I) $=-1 /(n-1)$ is its theoretical expectation, at the significance level of $0.05(0.01), \mathrm{Z}(\mathrm{I})=1.65$ is a critical value, greater than the critical value indicates that there is a significant spatial agglomeration effect.

Since Moran's I can only find spatial aggregation patterns of similar values (positive correlation) or dissimilarity observations (negative correlation) [29]. In order to further measure the high-value aggregation or low-value aggregation characteristics of the healthy environment level, Getis-Ord G* statistics are used.

$$
\mathrm{G}_{\mathrm{i}}^{*}(\mathrm{~d})=\sum_{\mathrm{i}=1}^{\mathrm{n}} \mathrm{W}_{\mathrm{ij}}(\mathrm{d}) \mathrm{X}_{\mathrm{i}} / \sum_{\mathrm{i}=1}^{\mathrm{n}} \mathrm{X}_{\mathrm{i}}
$$

In the formula, the value of $\mathrm{G}_{\mathrm{i}}{ }^{*}(\mathrm{~d})$ is significantly positive, indicating that the value around the $\mathrm{i}$ area is relatively high, which belongs to the hot spots area, otherwise, it is the cold spots area. $\mathrm{X}_{\mathrm{i}}$ is the observed value in the $\mathrm{i}$ area, $\mathrm{W}_{\mathrm{ij}}$ is the spatial weight matrix [1]. 


\subsubsection{Multiple regression model}

The paper studies the influencing factors of China's 31 provincial health environment levels in 2017, based on Woodridge's econometric theory, considers the establishment of econometric models, and carries out multiple regression analysis of cross-sectional data, in order to carry out effective economic interpretation and reduce model differences. Variance requires logarithmic processing of large integer data [31], the model expression relationship is as follows.

$$
\operatorname{LnY}=\beta_{0}+\beta_{1} \operatorname{Ln} X_{1}+\beta_{2} \operatorname{Ln} X_{2}+\beta_{3} \operatorname{Ln} X_{3}+\beta_{4} X_{4}+\beta_{5} X_{5}+\beta_{6} X_{6}+\beta_{7} \operatorname{Ln} X_{7}+u
$$

Among them, $\mathrm{i}(\mathrm{i}=0,1,2 \ldots 7$ ) is the model coefficient to be estimated, $\mathrm{u}$ is the error (interference term), $Y$ is the dependent variable, and $X_{i}(i=1,2 \ldots 7)$ is the independent variable of each influencing factor.

\section{Construction of a Healthy Environment Indicator System}

The thesis researches on the latest health and environment index system published by the World Health Organization (WHO), the National Health Commission, national health departments at the provincial, municipal (state) level, and personal literature at various scales, such as 'WHO Healthy City Index System', 'National Healthy City Index 2018 Edition', 'Healthy Beijing 2030 Planning Outline, Action Plan (2018-2020)', on the basis of these systems, combined with the common characteristics of indicators, the availability of data and the scientific nature, a healthy environment indicator system for the article was constructed. Compared with previous studies on indicator systems such as human settlements [20], environmental friendliness [32], the indicator system constructed in this article pays more attention to the health-oriented role and is more in line with the requirements of the current era. The health and environment index system is divided into three levels, the target level, the element level, and the index level, which are composed of five element level indicators of air, water quality, green space, waste disposal, and basic public facilities, Excellent days of urban air quality, average concentration of ambient air particulate matter (PM2.5) and other 13 indicator-level indicators for stratified measurement. In the index layer indicators, except that the average concentration of ambient air particulate matter (PM2.5) is a negative indicator, the larger the value, the lower the healthy environment level, and the others are positive indicators (Table 1).

Table 1 Index system of health and environment

\begin{tabular}{|c|c|c|c|c|c|}
\hline Target layer(A) & $\begin{array}{l}\text { Element } \\
\text { layer(B) }\end{array}$ & Index layer(C) & $\begin{array}{c}\text { Entropy- } \\
\text { weight(D) }\end{array}$ & $\begin{array}{c}\text { AHP } \\
\text { weight } \\
\text { (E) }\end{array}$ & $\begin{array}{l}\text { Compound } \\
\text { weight(F) }\end{array}$ \\
\hline & \multirow[t]{2}{*}{ Air B1 } & Excellent days ratio of urban air quality c1 & 0.1054 & 0.1554 & 0.2371 \\
\hline & & $\begin{array}{c}\text { Average concentration of ambient air particulate } \\
\text { matter c2 }\end{array}$ & 0.0740 & 0.1554 & 0.1664 \\
\hline & \multirow[t]{2}{*}{$\begin{array}{c}\text { Water } \\
\text { quality B2 }\end{array}$} & $\begin{array}{l}\text { The surface water quality meets the standard or } \\
\text { better than the ratio of Class III water body c3 }\end{array}$ & 0.0644 & 0.1661 & 0.1549 \\
\hline & & Urban sewage centralized treatment rate c4 & 0.0445 & 0.1661 & 0.1069 \\
\hline Health & \multirow[t]{2}{*}{$\begin{array}{c}\text { Green } \\
\text { space B3 }\end{array}$} & Green coverage of built-up area c5 & 0.0839 & 0.0236 & 0.0287 \\
\hline and & & Park area per capita c6 & 0.0602 & 0.0945 & 0.0823 \\
\hline $\begin{array}{l}\text { Environmental } \\
\text { Indicators }\end{array}$ & \multirow{4}{*}{$\begin{array}{c}\text { Waste } \\
\text { Treatment } \\
\text { B4 }\end{array}$} & $\begin{array}{l}\text { Harmless treatment rate of municipal solid waste } \\
\text { c7 }\end{array}$ & 0.0304 & 0.0960 & 0.0423 \\
\hline \multirow[t]{6}{*}{ A1 } & & $\begin{array}{c}\text { Comprehensive utilization rate of general } \\
\text { industrial solid waste c8 }\end{array}$ & 0.0392 & 0.0594 & 0.0337 \\
\hline & & Number of public toilets per 10,000 people c9 & 0.1698 & 0.0228 & 0.0560 \\
\hline & & Rural sanitary toilet penetration rate c10 & 0.0719 & 0.0105 & 0.0109 \\
\hline & \multirow{3}{*}{$\begin{array}{c}\text { Basic } \\
\text { public } \\
\text { facilities } \\
\text { B5 }\end{array}$} & Road area per capita c11 & 0.0596 & 0.0049 & 0.0042 \\
\hline & & Number of buses per 10,000 people c 12 & 0.1687 & 0.0285 & 0.0696 \\
\hline & & Clean energy (gas) penetration rate c13 & 0.0281 & 0.0167 & 0.0068 \\
\hline
\end{tabular}

* Note: The indicators are derived from international, national, provincial, city (state) official releases and 
existing documents related to the environment of the healthy city system.

\section{Research Results}

\subsection{Healthy environment level and spatial pattern}

In order to evaluate the health environment level of various regions in China, combined with the composite weights (Table 1), a comprehensive score was calculated, and Arcgis 10.2 was used to classify China's 2017 health environment level by using natural breakpoint grading, which was classified as high level area, higher level area, middle level area, lower level area, low level area, the spatial visual expression is as follows (Figure 1).

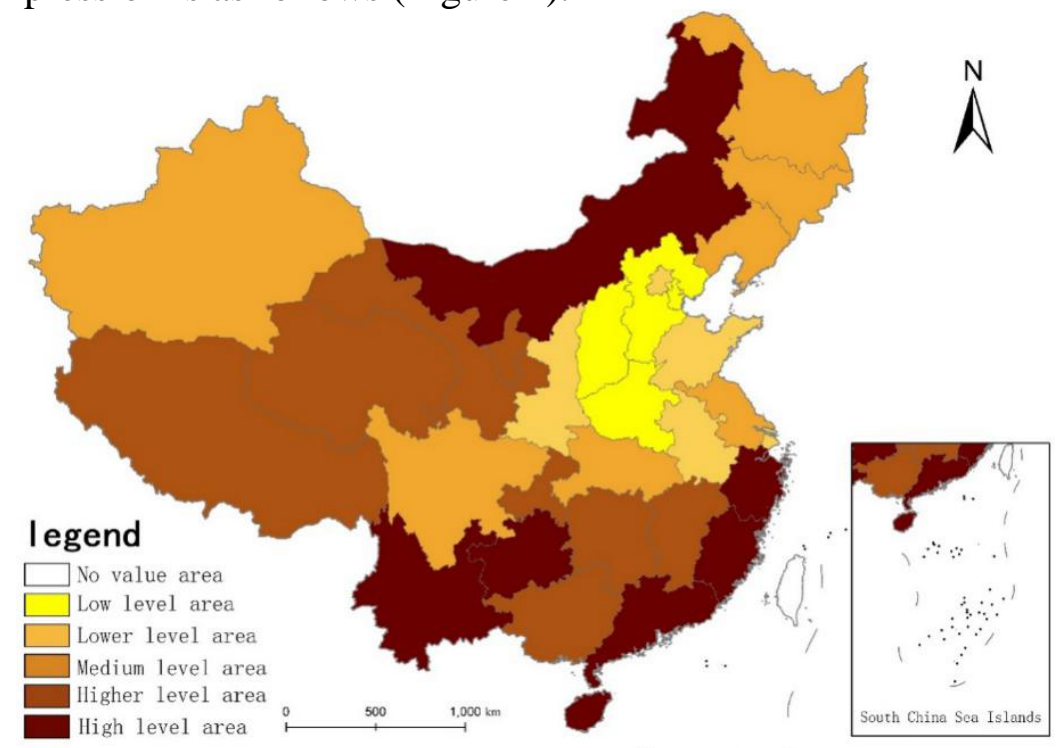

Figure 1 Overall spatial distribution of health and environment level in China 2017.

On the whole, China's health environment level in 2017 is mainly at a higher level, with significant spatial differences in the east, middle and west. The high-level areas are distributed in the north, southwest and southeast coastal areas, includes Inner Mongolia, Yunnan, Guizhou, Zhejiang, Fujian, Guangdong, and Hainan, accounted for $22.58 \%$. The higher-level areas have the largest number of provinces, with the central and western regions mainly regional, includes Jiangxi, Hunan, Guangxi, Chongqing and Ningxia, Gansu, Qinghai, and Tibet, accounted for 25.81\%. Medium-level areas are distributed in the east, middle, west, and northeast regions, and are more dispersed, includes Jiangsu , Hubei, Sichuan, Xinjiang, Heilongjiang, Jilin, and Liaoning provinces, accounted for $22.58 \%$. The lower level areas are concentrated in the central and eastern regions, includes Shaanxi, Anhui, Shandong, Beijing, and Shanghai, accounted for 16.13\%. Low-level areas mainly includes Shanxi, Henan, Hebei, and Tianjin, and are distributed in North China, accounted for $12.90 \%$.

\subsection{Space aggregation of healthy environment}

Geoda1.14.0 was used to calculate the spatial autocorrelation coefficient of China's healthy environment level in 2017, the index is 0.4819 , passed the test at $1 \%$ significance level, and the $\mathrm{Z}$ statistic is equal to 5.0490 , which is greater than the critical value of 1.65 . This indicates that the healthy environment level has a positive spatial autocorrelation, there is a spatial agglomeration effect.

From the perspective of the spatial pattern of cold spots and hot spots in G* statistics, the spatial pattern of China's healthy environmental level in 2017 is significantly different, and can be divided into cold spots and hot spots. Low-value cold spots are mainly distributed in North China and surrounding provinces (Figure 2), includes Inner Mongolia, Ningxia, Shanxi, Shanxi, Henan, Shandong, Hebei, Beijing, Tianjin and Liaoning. High-value hot spots are mainly concentrated in southern coastal areas, includes Guangdong, Guangxi and Hainan. It is worth noting that the 
number of provinces in cold spots and hot spots accounted for $32.26 \%$ and $9.68 \%$ of the total number of studies, respectively, the level of high-value agglomeration is low.

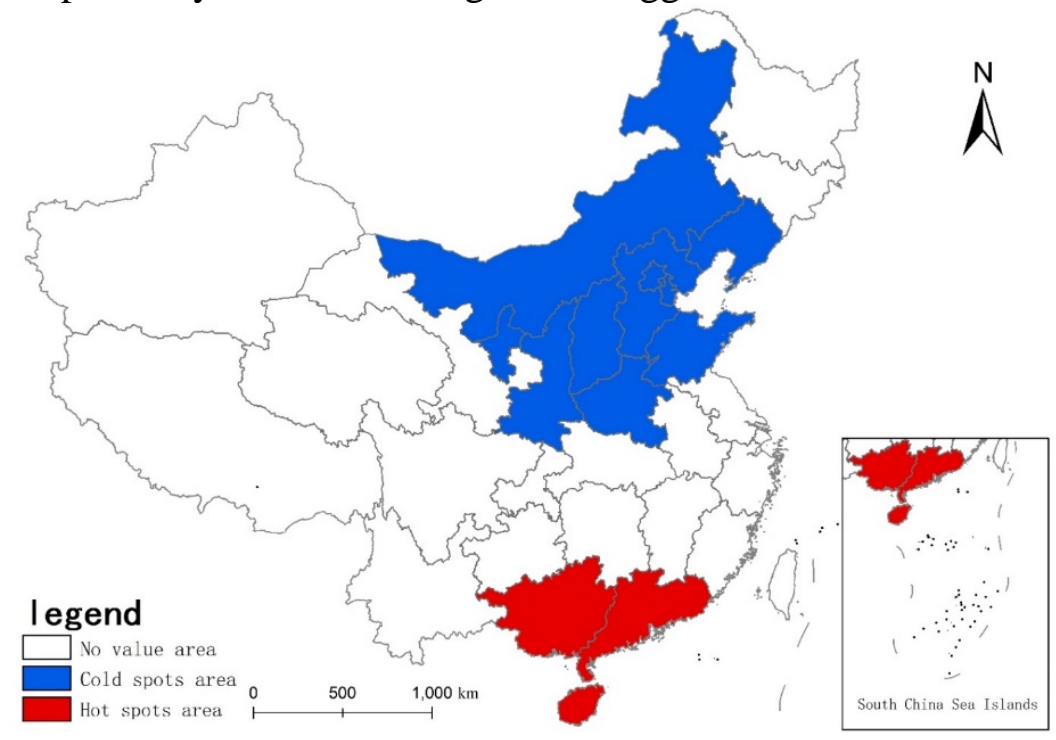

Figure 2 Distribution of cold spots and hot spots health environment values indicators in China 2017.

\section{Analysis of Influencing Factors}

\subsection{Variable selection}

The health environment index system established in the paper is closely related to the built environment. Based on the previous research, the article believes that the health environment level is related to regional economic, industrial structure, social and demographic factors, and makes assumptions about the expected impact of each factor, as shown in the table 2.

Table 2 Variable interpretation

\begin{tabular}{|c|c|c|c|}
\hline Influencing factors & $\begin{array}{c}\text { Variable } \\
\text { abbreviation }\end{array}$ & Variable description and unit & Suppose \\
\hline \multirow{5}{*}{$\begin{array}{l}\text { 1. Economic factors } \\
\text { 2. Industrial structure } \\
\text { factors }\end{array}$} & Ln: (GPC) & $\mathrm{X}_{1}$ :GDP per capita (Yuan) & + \\
\hline & Ln:(PCDIOUR) & $\begin{array}{c}\mathrm{X}_{2} \text { :Per capita disposable income of urban } \\
\text { residents (Yuan) }\end{array}$ & + \\
\hline & Ln: (PCDIOF) & $\begin{array}{c}\mathrm{X}_{3} \text { :Per capita disposable income of } \\
\text { farmers (Yuan) }\end{array}$ & + \\
\hline & (POGITSI) & $\begin{array}{c}\mathrm{X}_{4} \text { : Proportion of GDP in the secondary } \\
\text { industry (\%) }\end{array}$ & - \\
\hline & (POGOTI) & $\begin{array}{c}\mathrm{X}_{5}: \text { Proportion of GDP in the Tertiary } \\
\text { Industry (\%) }\end{array}$ & + \\
\hline 3. Social factors & (POUP) & $\begin{array}{c}\mathrm{X}_{6} \text { : Proportion of urban population at the } \\
\text { end of the year }(\%)\end{array}$ & - \\
\hline 4. Demographic factors & Ln: (PD) & $\begin{array}{c}\mathrm{X}_{7} \text { : Population density (person / square } \\
\text { kilometer) }\end{array}$ & - \\
\hline
\end{tabular}

* Note, the variable data comes from the 'China Statistical Yearbook' in 2018, population density, total population at the end of the year / area of administrative area.

\subsection{Regression results}

In order to eliminate the multicollinearity between the variables, the backward screening stepwise regression method is used to eliminate the insignificant variables and various statistical tests based on estimator variance are no longer invalid, established prediction interval is also more reliable, Heteroscedasticity-robust standard error would be used for parameter estimation [33], and Eviews 7.2 would be used to analyse the multiple regression model, the results are as follows (Table 
3).

It can be seen from the preliminary regression results that $\mathrm{R}^{2}$ is $48.16 \%$, adjusted $\mathrm{R}^{2}$ is $32.39 \%$, the corresponding $\mathrm{F}$ statistic is 3.05 , and $\mathrm{P}$ value $=0.02$, indicates that the model passed the test at the $5 \%$ significance level. Among the independent variables, urban per capita disposable income and the proportion of secondary and tertiary industries have passed the significance test, per capita GDP, per capita disposable income of farmers, urbanization rate and population density have not passed the significance test. In particular, the per capita GDP has no significant impact on the health environment level, and the urban per capita disposable income has an excessively high impact on the health environment level, which obviously does not meet the economic significance. Considered the model may have multiple collinear. Generally, the variance expansion factor VIF $=10$ is used as the critical value, and greater than 10 indicates that the independent variable has multicollinearity [31]. Used Eviews7.2 to calculate the variance expansion factor VIF value of each dependent variable, confirmed the existence of multi-collinearity between variables, therefore, some independent variables are screened out.

After stepwise regression, used the heteroscedasticity-standard error regression model, $\mathrm{R}^{2}$ is $41.33 \%$, adjusted $\mathrm{R}^{2}$ is $32.30 \%$, the corresponding $\mathrm{F}$ statistic is 4.58 , and $\mathrm{P}$ value $=0.00$, the model passed the significance test. Urban per capita disposable income, the proportion of GDP in the secondary and tertiary industries, population density and the level of the healthy environment are significant. They pass the test at a $1 \%$ significance level and can provide a better explanation for the dependent variable. The final optimization model is as follows.

$$
\operatorname{LnY}=-6.5442+0.9082 \operatorname{LnX}_{2}-0.0299 \mathrm{X}_{4}-0.0382 \mathrm{X}_{5}-0.0670 \operatorname{LnX}_{7}
$$

Table 3 The results of regression estimate.

\begin{tabular}{c|c|c|c|c|c}
\hline \multirow{2}{*}{ Variable } & \multicolumn{2}{|c|}{ Preliminary regression estimate } & & \multicolumn{2}{c}{$\begin{array}{c}\text { Robust-standard error regression estimates } \\
\text { after stepwise regression }\end{array}$} \\
\cline { 2 - 6 } & Coefficient & P value & & Coefficient & P value \\
\hline Ln:GPC & 0.1509 & 0.6282 & & & 0.0046 \\
\hline Ln:PCDIOUR & $1.2914^{* *}$ & 0.0112 & & $0.9082^{* * *}$ & \\
\hline Ln:PCDIOF & -0.5835 & 0.1095 & & & 0.0006 \\
\hline POGITSI & $-0.0341^{* * *}$ & 0.0030 & & $-0.0299^{* * *}$ & 0.0013 \\
\hline POGOTI & $-0.0446^{* * *}$ & 0.0031 & & $-0.0382^{* * *}$ & \\
\hline POUP & 0.0041 & 0.6321 & & & 0.0091 \\
\hline Ln:PD & -0.0556 & 0.1383 & & $-0.0670^{* * *}$ & \\
\hline $\mathrm{R}^{2}$ & 0.4816 & & & 0.4133 & \\
\hline Adjust $\mathrm{R}^{2}$ & 0.3239 & & & 0.3230 & 0.0062 \\
\hline F Statistics & 3.0529 & 0.0200 & & 4.5787 & \\
\hline
\end{tabular}

* Note, $* * *, * *$, and $*$, indicate significance levels of $0.01,0.05$, and 0.1 , respectively.

\subsection{Results analysis}

\subsubsection{Urban per capita disposable income}

According to Maslow's hierarchy of needs theory, people's needs are a process from physiological needs to spiritual levels that need to rise step by step. The increase in per capita disposable income in cities and towns means that on the basis of solving basic needs for life, people can improve more spiritual enjoyment requires investment and consumption, such as a healthy and comfortable living environment. It can be seen from the results that the urban per capita disposable income has a significant positive effect on the health environment level. When the urban per capita disposable income increases by $1 \%$, the health environment level would increase by $90.82 \%$, which is consistent with the assumptions. As the income level of urban residents increases, people would have stronger spiritual needs for leisure and health, and would have higher standards for the quality of the living environment, at the same time, the increase in income would prompt people to invest more in education and the health awareness would gradually increase, it can promote the willingness and behaviour to improve the healthy living environment [34]. 


\subsubsection{Industrial structure}

Generally speaking, the secondary industry is dominated by processing and manufacturing industries, large industrial and mining enterprises emit large amounts of exhaust gas, waste water, and waste residues, which would cause serious environmental pollution. The tertiary industry is dominated by service industries, the impact of the environment should be small, and relevant scholars also believe that the tertiary industry has a positive effect on improving the water environment and atmospheric environment [35]. The empirical results show that the proportion of GDP in the secondary and tertiary industries has a significant negative effect on the level of the healthy environment, confirming the assumption that the secondary industry has a negative effect on the healthy environment, but the proportion of the tertiary industry does not meet expectations. According to the regression semi-elasticity coefficient, it can be seen that when the percentage of secondary and tertiary industries increases by one percentage point, the level of healthy environment would decrease by $2.99 \%$ and $3.82 \%$, respectively. On the one hand, the increase in the size of industrial enterprises has a positive effect on environmental pollution, leading to more serious environmental pollution [36], On the other hand, due to the strong relevance of the tertiary industry, it is often comprehensive and would also cause pollution to the environment. For example, the large-scale use of disposable packaging products in the catering and hotel industries, the discharge of pollutants caused by transportation and other industries, and the irregular disposal of public waste and other issues. Under the healthy environment index system in this article, the tertiary industry not only has a negative effect on the healthy environment, but also has a greater negative impact than the secondary industry, which deserves our further attention.

\subsubsection{Population density}

Population density reflects the number of regional populations. Under the same unit area, the greater the density, the greater the population, and the greater the concentration, which would also bring a series of human activities and environmental impacts, such as industrial agglomeration, land development Pollution and damage to the environment caused by other activities. The regression results confirm this hypothesis. The population density has a negative effect on the healthy environment. For every 1\% increase, the healthy environment level would decrease by $6.70 \%$, which shows that the environmental quality level is affected to a certain extent by the population density. Increased population density means increased production activities, such as construction, catering, transportation and other industries would cause fine particulate matter (PM2.5) emissions [37], caused pollution to air quality levels, and thereby affected the overall level of healthy environment.

\subsubsection{Other factors}

The other three factors have no obvious significant correlation with the level of healthy environment, which is different from the expected assumption, 1). Assumed that the increase in GPD per capita means the expansion of economic scale, which is conducive to providing financial support for the creation of a healthy environment and has a positive effect. However, studies have shown that economic growth and environmental protection are a pair of contradictory communities. For example, the increase in industrial output would promote the accumulation of local economic aggregates and increase per capita GDP, this often represents an increase in people's income levels would increase the demand for a quality environment, but on the other hand, it would also increase the degree of environmental pollution [38-39], brought resistance to environmental protection. Under the influence of the above two factors, the impact of GDP per capita on the healthy environment has no significant relationship, 2). Due to the existence of the dual urban-rural structure in China, the urban-rural income gap is still obvious. Compared with the disposable income of urban residents, the disposable income of rural residents is relatively low, and it has not played a significant role in improving the health environment, and the lack of rural indicators in the health environment assessment index system is also a possible cause of insignificance, 3). The increase in the level of urbanization is usually accompanied by population agglomeration, which 
means that the increase in population density would have a negative impact, but the results show that this assumption is not true. Urbanization is the result of comprehensive factors. The optimization of industrial structure, the advancement of environmental protection technology, and the increase in awareness of environmental protection behaviours would have a positive effect on the health environment level of air, water quality, and green space. At the same time, the urbanization of the population, economic development, and the expansion of land use area would also brought environmental damage [40-41], which shows that the impact of urbanization on the health environment level is multi-faceted, and the health environment level is not only a unilateral impact, We need to analyse from more angles.

\section{Conclusion and Discussion}

\subsection{Conclusion}

In 2017, the overall health environment level in China was significantly different in the east, middle and west regions. The high-level regions were mainly distributed in the southwest region, southeast coast and Inner Mongolia, the middle level area is distributed in the east, middle, west and northeast areas, showed irregular characteristics, while the low level area is more concentrated, mainly in the provinces of North China, and the health environment level has significant spatial agglomeration characteristics. From the perspective of the overall hot spots and cold spots distribution of the healthy environment, there are obvious high-value gathering areas in the southern coast, and most of the North China region and some provinces in the Northeast are low-value gathering areas.

Among the seven influencing factors selected, urban per capita disposable income, the proportion of secondary and tertiary industries in GDP, population density have a significant correlation with the level of health environment, which is an important factor affected the level of health environment in China. Urban per capita disposable income has a positive effect on the health environment level, secondary and tertiary industries account for the proportion of GDP, and population density has a negative effect. Among them, urban per capita disposable income has the greatest impact on the health environment.

\subsection{Discussion}

Modern economic activities have made people's connections closer, and the scope of activities is expanded in space. From the perspective of public health, it means that the risk of disease transmission also increases, which affects people's health, and improves environmental quality will help to avoid this situation and also improve the level of modern space governance. On the basis of understanding previous studies on the impact of the environment on population health [12,14], the article further builds on the creation of a health-oriented living environment through the construction of an indicator system, highlights the concept of health, and echoes the current theme of 'Healthy China'. By establishing a healthy environment indicator system, the 2017 healthy environment level is measured, Using GIS spatial visualization technology and spatial autocorrelation models to express the health environment level spatially is conducive to a comprehensive understanding of the spatial distribution characteristics of China's health environment level in 2017, at the same time, an econometric model is established to explore the factors that affect the level of the healthy environment, it can make the analysis results more credible, and provides reference for the coordinated development of China's economy and environmental protection.

The paper also has limitations and can be further studied from the followed three aspects, limited to the availability of data, the health and environment indicator system can be further improved. In the future, indicators such as environmental noise and the relevant environment in rural areas can be added to make the health environment indicator system more comprehensive. In addition, natural factors such as terrain and climate and more socio-economic factors can be added to have a more comprehensive understanding of the factors that affect the level of the healthy environment, more 
years of data can be added to the panel of spatial and temporal differences data analysis to understand the dynamic changes of China's health environment level and whether it has space spillover effects.

\section{References}

[1] Zhao Xueyan, Wang Weijun, and Wan Wenyu. Regional Inequalities of Residents' Health Level in China: 2003-2013. Acta Geographica Sinica, 2017, 72(4), 685-686, 688-689.

[2] Wang Cuiting, and Xie Youhong. Investigation and Analysis on Incidence of Infectious Respiratory Diseases in Different Urbanized Areas in Chongqing City. Chinese Journal of Disease Control \& Prevention, 2015, 19(1), 50-53.

[3] Tang Decai. Industrialization, Industry Structure and Environment Pollution- Based on Manufacturing Industry and Regional Panel Model. Soft Science, 2009, 23(10), 6-11.

[4] Ao Rongjun, Li Haoci, Yang Zhen, and Zhang Tao. Spatial Differentiation and Influencing Factors of Health Level of the Elderly Population: A Case Study of Hubei Province. Progress in Geography, 2017, 36(10), 1218-1228.

[5] Liu Xiaoxia, Zou Xiaohua, Wang Xingzhong. Progress of Health Geography in Western Countries. Human Geography, 2012, 27(3), 23-24.

[6] Yang Linsheng, Li Hairong, Li Yonghua, Wang Wuyi, and Tan Jianan. Progress of Medical Geography and Environmental Health Studies. Progress in Geography, 2010, 29(1), 31-44.

[7] Kearns, R. F. Place and Health, Towards a Reformed Medical Geography. The Professional Geographer, 1993, 45(2), 139-147.

[8] Hu Hong, and Xu Jiangang. Progress in Urban Health Geography Using Complexity Theory. Human Geography, 2018, 33(6), 1-8.

[9] Wang Yingjia, and Luo Yongjun. Research on the in Fluence of High Altitude Physical Geographical Environment on Human Health and Protective Measures. Foreign Medical Science Section of Medgeography, 2015, 36(2), 99-101.

[10] Rundle, A. F., Diez Roux, AV. S., Free, LM. T., Miller, D. F., Neckerman, KM. F., and Weiss, CC. S. The Urban Built Environment and Obesity in New York City, A Multilevel Analysis. American Journal of Health Promotion, 2007, 21(4s), 326-334.

[11] Sun Bindong, Yan Hong, and Zhang Tinglin. Impact of Community Built Environment on Residents' Health: A Case Study on Individual Overweight. Acta Geographica Sinica, 2016, 71(10), 1721-1730.

[12] Dai Yingyi, Zhu Zhanqiang, and Zhou Suhong. The Effects of Green Space on Leisure Time Physical Activities from the Perspective of Community Differentiation, A Case Study of Guangzhou, China. Tropical Geography, 2019, 39 (2), 237-246.

[13] Rita Berto. Exposure to Restorative Environments Helps Restore Attentional Capacity. Journal of Environmental Psychology, 2005, 25(3), 249-259.

[14] Tan Shaohua, Guo Jianfeng, and Zhao Wanmin. Research Progress of Restoration and Stress Relief Benefits in Urban Natural Environment. Areal Research and Development, 2010, 29(4), 55-60.

[15] Sun Hongmei, and Sun Qiang. Research Progress of Built Environment Effect on Adolescent's Physical Activity. Journal of Shandong Sport University, 2018, 34(4), 87-92.

[16] Zheng Zhenhua, and Peng Xizhe. The Impact of Community Environment on Behavior and Health of the Elderly, Group Comparison of Different Ages. Geographical Resarch, 2019, 38(6), 1481-1496. 
[17] Li Haiying, Song Yanliqing, Li Guo, and Wang Zhuying. The Relationship between Urban Built Environment and Physical Activity of Middle-Aged and Old Residents. Chinese Journal of Gerontology, 2017, 37(19), 4896-4899.

[18] Chen Chun, Hailili Tajnur, and Chen Yong. Built Environment's Influence on Obesity of the Older Women and Its Planning Responses. Human Geography, 2018(4), 76-81.

[19] Zhou Kan, and Fan Jie. Regional Disparity of Environmental Pollution Source and its Socio-economic Influencing Factors, Based on the Cross-section Data of 339 Cities at Prefecture Level or above in China. Acta Geographica Sinica, 2016, 71(11), 1911-1912, 1912-1913.

[20] Ye Yiguang, and Zhou Yaoping. Towards Building Urban Residential Environment Evaluation Index System. Journal of Nanjing Agricultural University (Social Sciences Edition), 2004, 4(1), 41-42.

[21] Liu Ran. Urban Riverfront Cycling Greenway Planning and Design Based on Healthy Environment Construction-Take HAIBO River in Qingdao as an Example. Qingdao University of Technology, Shandong, 2018.

[22] Wang Huiting. Research on Improvement of Non-motorized Traffic Environment Based on Healthy City Concept. Hefei University of Technology, Anhui, 2019.

[23] Pratyusha Basu, and Jayajit Chakraborty. Environmental Justice Implications of Industrial Hazardous Waste Generation in India: A National Scale Analysis. Environmental Research Letters, 2016, 11(12), 125001.

[24] Christopher Ambrey, Jason Byrne, Tony Matthews, Aidan Davison, Chloe Portanger, and Alex Loe. Cultivating Climate Justice: Green Infrastructure and Suburban Disadvantage in Australia. Applied Geography, 2017, 89, 52-60.

[25] Shen Jing, and Zhou Chuping. A Review of Foreign Research on Environmental Justice. Tropical Geography, 2019, 39(2), 298-308.

[26] Zhang Yanji, Qin Bo, and Tang Jie. The Impact of Urban Built Environment on Residential Physical Health: Based on Propensity Score Matching. Acta Geographica Sinica, 2018, 73(2), 333-345.

[27] Li Shuai, Wei Hong, Ni Xilu, Gu Yanwen, and Li Changxiao. Evaluation of Urban Human Settlement Quality in Ningxia Based on AHP and the Entropy Method. Chinese Journal of Applied Ecology, 2014, 25(9), 2700-2708.

[28] Chen Mingxing, Lu Dadao, and Zhanghua, Comprehensive Evaluation and the Driving Factors of China's Urbanization. Acta Geographica Sinica, 2009, 64(4), 387-398.

[29] Song Xueqian, and Deng Wei. Public Services in Mountainous Areas: Spatial Disparity and Efficiency Enhancement. Science Press, Beijing, 2019.

[30] Zhang Songlin, and Zhang Kun. Comparison between General Moran’s Index and Getis-Ord General G of Spatial Autocorrelation. Acta Scientiarum Naturalium Universitatis Sunyatseni, 2007, 46(4), 93-97.

[31] Jeffrey, M. Wooldridge. Introductory Econometrics-A Modern Approach (Fifth Edition). Fifth Edition. China Renmin University Press, Beijing, 2015.

[32] Zhang Xinduan, and Zheng Zegen. Study on the Environmental Indicator Systems of Environment-Friendly City. Environmental Science and Management, 2007, 32(9), 53-56.

[33] Li Zinai, and Pan Wenqing. Econometrics. Third Edition. Higher Education Press, Beijing, 2010.

[34] Li Guozhi. Influencing Factors of Urban Residents Willingness to Pay for Ecological Compensation of Public Welfare Forests. Journal of Arid Land Resources and Environment, 2016, 
30(11), 98-102.

[35] Wang Wenzhe, and Han Yugang. An Empirical Analysis of the Impact of the Evolution of Industrial Structure on the Ecological Environment in Anhui Province. Statistics \& Decision, 2017(8), 142-145.

[36] Zhang Ruiping. Empirical Analysis on Impact of Industrialization to Environment Effect. Resource Development \& Market, 2015, 31(8), 928-931.

[37] Xiang Jiae, Xu Lihua, Zhang Fangfang, Qiu Bubu, and Zhu Hong. Study on the Pollution Characters and Impact Factors of PM2. 5 and PM10 in Urban Hangzhou. Environmental Monitoring in China, 2016, 32(6), 36-42.

[38] Zeng Xiangang. Environmental Efficiency and Its Determinants across Chinese Regions. Economic Theory and Business Management, 2011(10), 103-110.

[39] Li Yingshan. Empirical Analysis on the Impact of Environmental Quality on the Economic Growth in Guangdong Province Based on the Kuznets Curve. Science and Technology Management Research, 2015(2), 237-241.

[40] Mu Huaizhong, and Fan Hongmin. The Impact of Urbanization on Environmental Quality -Based on Panel Data of 27 Countries. Urban Problems, 2016(9), 73-79.

[41] Jiang Lei, Zhou Haifeng, and Bai Ling. Impact of Urbanization on Urban Air Quality Based on Spatial Econometric Models. Tropical Geography, 2019, 39(3), 461-471. 